Journal for ImmunoTherapy of Cancer Butterfield LH, et al. Improving the therapeutic index in adoptive cell therapy: key factors that impact efficacy. Journal for ImmunoTherapy of Cancer 2020;8:e001619. doi:10.1136/ jitc-2020-001619

Accepted 16 September 2020

Check for updates

(C) Author(s) (or their employer(s)) 2020. Re-use permitted under CC BY-NC. No commercial re-use. See rights and permissions. Published by BMJ.

${ }^{1}$ Allogene Therapeutics, San Francisco, California, USA ${ }^{2}$ ESSA Pharma Inc, Redwood City, California, USA

${ }^{3}$ Research, Parker Institute for Cancer Immunotherapy, San Francisco, California, USA

${ }^{4}$ Microbiology and Immunology, University of California San Francisco, San Francisco, California, USA

${ }^{5}$ Research \& Development, Refuge Biotechnologies, Menlo Park, California, USA

Correspondence to Dr Francesco Marincola; WMP5353@gmail.com

Dr Ena Wang;

Ena.Wang@allogene.com

\title{
Improving the therapeutic index in adoptive cell therapy: key factors that impact efficacy
}

\author{
Ena Wang, ${ }^{1}$ Alessandra Cesano, ${ }^{2}$ Lisa H Butterfield (D) ${ }^{3,4}$ Francesco Marincola ${ }^{5}$
}

\begin{abstract}
The therapeutic index (TI) is a quantitative assessment of a drug safety proportional to its effectiveness. The estimation is intuitive when the engagement of the product with its target is dependent on stable chemistry and predictable pharmacokinetics as is the case for small molecules or antibodies. But for therapeutics with complex biodistribution and context-dependent potency such as adoptive cell therapy (ACT) products, $\mathrm{TI}$ estimations need to consider a broader array of factors. These include product-dependent variability such as functional fitness, unpredictable pharmacokinetics due to non-specific trapping, sequestration and extravasation into normal tissues and variable rates of in vivo expansion. In the case of solid malignancies, additional modifiers dependent on individual tumor immune biology may affect pharmacodynamics, including differential trafficking to benign compared with cancer tissue, hampered engagement with target cells, immune suppression and cellular dysfunction due to unfavorable metabolic conditions. Here, we propose a patient-specific assessment of factors affecting on-tumor from off-tumor activity in disparate immunologic environments that impact ACT's clinical efficacy and may favorably balance the TI. for ACT products.
\end{abstract}

\section{INTRODUCTION}

A paramount difference between most anticancer approaches and adoptive cell therapy (ACT) is the ill-defined impact of the therapeutic index (TI) in the latter due to the erratic pharmacokinetics and pharmacodynamics of cellular products. TI is defined as the ratio of a drug dose that produces toxicity over the one yielding a clinically effective response: $\mathrm{TI}=\mathrm{TD}_{50} / \mathrm{ED}_{50}$ (where $\mathrm{TD}_{50}$ is the dose that causes a toxic response in $50 \%$ of the population and $\mathrm{ED}_{50}$ is the dose therapeutically effective with the same prevalence). The estimation is intuitive when the effects of a given product strictly depend on its engagement with the respective target referred to, hereafter, as 'on-target effect'. A pathway inhibitor targeting the V600 mutation of BRAF presents with an optimal TI since targeting of the wild-type gene is minimal. By analogy, cytotoxic $\mathrm{T}$ lymphocytes (CTLs) directed against mutated proteins privately expressed by cancer cells will cause minimal on-target/ off-tumor toxicity. Conversely, when chimeric antigen receptor (CAR) engineered $\mathrm{T}$ cells are aimed at non-mutated self-proteins expressed by benign and neoplastic tissues, the TI tapers according to the differential in respective surface antigen density. Similar considerations apply to tumor-infiltrating lymphocytes (TILs) recognizing non-mutated lineage-specific or tumor-specific antigens.

The differential is nullified in B-cell malignancies targeted by anti-CD19 CAR-T cells. In this case, both normal and neoplastic cells express comparable surface densities of the differentiation marker and the therapeutic window is based on acceptance of the collateral depletion of normal B cells compensated by immunoglobulin replacement. ${ }^{1}$ When the function of the corresponding benign cells is irreplaceable, as for T-cell malignancies, this approach is unworkable. Differential surface antigen density becomes critical for CAR targets overexpressed by cancer cells such as the amplification of the human epidermal growth factor receptor 2 (HER2) gene. $^{2}$ Here, surface differences between neoplastic and benign tissues demarcate the ${ }^{3} \mathrm{TI}$

In analogy with small molecules and antibodies, the interaction between CAR-T cells or TILs and their targets can be reduced to a quasi-linear relationship when tested in controlled conditions such as in vitro cytotoxicity assays. Variability in product potency may still modulate the relationship but other factors related to the host or the tumor microenvironment (TME) can be disregarded. We observed that a tight quantitative correlation exists between the cytotoxic activity of naturally-occurring TILs and surface density of their cognate epitope. ${ }^{4}$ Assuming comparable distribution of adoptively transferred cells among tissues, this linearity could serve as a conceptual parameter to estimate the number of effectors required to kill benign 


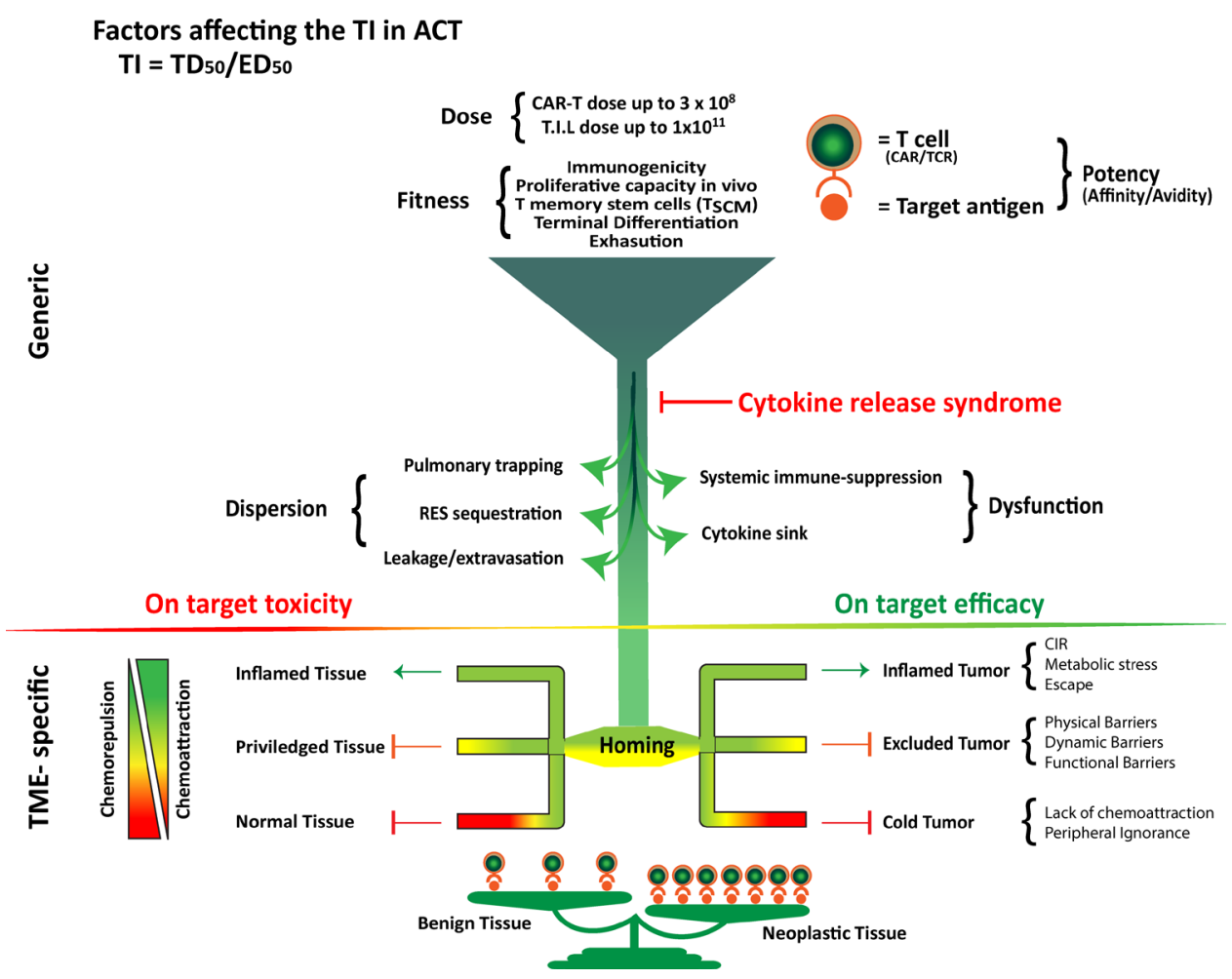

Figure 1 Generic and TME-specific factors that influence the deployment of ACT products in disparate immunologic environments. Generic modifiers include dose, potency and fitness of the product, and modifiers that may cause their dispersion or dysfunction even upstream of the crossroad that determines their homing in benign and neoplastic tissues. Target antigen expression becomes relevant only at the end of the process, when the colonizing $T$ cells reach the target tissue and deploy their residual effector cell potential. ACT, adoptive cell therapy; TME, tumor microenvironment.

cells expressing low densities of cognate antigen (toxic dose) compared with cancer cells expressing higher densities (effective dose). For ACT, however, things are not that simple and we argue that even in the hypothetical condition where the TI=1 (no difference between TD and ED), other factors sway the balance between toxicity and effectiveness (figure 1). In this commentary, we will focus pre-eminently on key factors that impact ACT's clinical efficacy and contribute to a favorable balance in the TI calculation by improving the selection, monitoring and follow-up of patients according to their individual immune biological status.

Generic factors can modulate toxicity and effectiveness upstream of the junction that regulates differential T-cell distribution in benign versus malignant tissues (table 1). To fully exploit a favorable TI, the least dose estimated to yield a desired therapeutic objective should be administered to minimize the chances of toxicity. However, conditions orthogonal to on-target activity can affect the estimate including the 'potency' of the product. Potency, characterized at the time of administration, is the capacity of a product to affect a given result. For $\mathrm{T}$ cells, potency depends partially on the binding affinity of the T-cell receptor (TCR) or the CAR for the respective epitope. Avidity, the intrinsic capacity of the product to recognize its target, results from TCR/CAR affinity, their expression levels and the functional status of the T cells, which determine the threshold for activation. Moreover, the level of differentiation, functional status and responsiveness to modulatory or chemoattractive signals affects CTLs 'fitness' to proliferate, expand, persist and function after infusion. ${ }^{5-7}$ Enrichment of ACT products with selfsustaining T memory stem cells endowed with self-renewal aptitude and the capacity to reconstitute the entire spectrum of CTL subsets ${ }^{8}$ may increase the TI by decreasing the number of circulating cells required for optimal trafficking and expansion in the TME.

Immunogenicity may affect persistence because humoral or cellular responses may neutralize the therapeutic, particularly in the case of allogeneic products or those containing heterologous, non-fully humanized or heavily engineered proteins. ${ }^{9}$

On-target deployment may be skewed by dispersion of ACT products caused by trapping in the pulmonary circulation, sequestration in the reticuloendothelial system (RES), extravasation into interstitial spaces, 'cellular sinks' for homeostatic cytokines or the immune-suppressive effect of the tumor-bearing status. ${ }^{10-14}$ Critchley-Thorne $e t$ $a l^{15}$ observed that the response of circulating lymphocytes to interferon (IFN) stimulation is frequently dampened in patients with cancer. The degree of dysfunction is patientspecific, determined by an indirect effect of cancer cell bioproducts ${ }^{16}$ and it is reversible ex vivo. It is consequential to postulate that CTL function may be quenched soon after reinfusion in such patients. To our knowledge, this has never been addressed by clinical trials. 
Table 1 Factors affecting the TI of ACT products

$\begin{array}{ll}\text { Generic factors } & \begin{array}{l}\text { Affinity for target, } \\ \text { stemness, exhaustion, } \\ \text { terminal differentiation and } \\ \text { immunogenicity }\end{array} \\ \text { Dispersion } & \begin{array}{l}\text { Trapping in the lungs, } \\ \text { sequestration in the RES, } \\ \text { leakage and extravasation }\end{array} \\ \text { Dysfunction } & \begin{array}{l}\text { Systemic immune suppression } \\ \text { and cytokine sink }\end{array} \\ \text { Circumstantial factors } & \begin{array}{l}\text { Supportive combinatorial } \\ \text { therapies, comorbidities and } \\ \text { microbiome }\end{array} \\ \text { Off-target toxicity } & \begin{array}{l}\text { Cytokine release syndrome and } \\ \text { neurotoxicity }\end{array}\end{array}$

TME-specific factors

\begin{tabular}{|c|c|}
\hline Antigen availability & $\begin{array}{l}\text { Differential in antigen density, } \\
\text { availability and accessibility } \\
\text { between benign and neoplastic } \\
\text { tissues }\end{array}$ \\
\hline Trafficking to tumor & Chemoattractive gradient \\
\hline Engagement and exclusion & $\begin{array}{l}\text { Physical, functional } \\
\text { and dynamic barriers- } \\
\text { chemorepulsive gradient, } \\
\text { transient checkpoint } \\
\text { upregulation in response to } \\
\text { IFN-g secretion }\end{array}$ \\
\hline Immune suppression & $\begin{array}{l}\text { Checkpoint cluster, regulatory } \\
\text { T cells, myeloid suppressor } \\
\text { cells and immune suppressive } \\
\text { metabolites }\end{array}$ \\
\hline Nutrient depletion & $\begin{array}{l}\text { Hypoxia, hypoxia-induced } \\
\text { suppressive factors, reduced } \\
\text { glucose, amino acid or fatty } \\
\text { acid fuels and acidic milieu }\end{array}$ \\
\hline Peripheral ignorance & $\begin{array}{l}\text { Combined lack of } \\
\text { chemoattraction and immune- } \\
\text { stimulation of adoptively } \\
\text { transferred T cells }\end{array}$ \\
\hline
\end{tabular}

ACT, adoptive cell therapy; IFN, interferon; RES, reticuloendothelial system; TI, therapeutic index; TME, tumor microenvironment.

Another generic modifier affecting the TI is the uncontrolled and unpredictable release of cytokines resulting from non-specific interactions between administered and endogenous cells leading to cytokine release syndrome (CRS) or other off-target toxicities such as neurotoxicity. ${ }^{17}$ Finally, the genetic background of the patient and other hidden circumstantial factors related to the host's history play a subtle and unquantifiable role in sculpting CTL function in vivo. ${ }^{18}$

A dramatic example of discrepancy between administered dose of effector cells and their on-target deployment was described by Pockaj et $a l^{13}$ decades ago. TILs adoptively transferred in patients with metastatic melanoma were labeled with radioactive ${ }^{111}$ Indium to trace their body distribution. In 12 of 38 patients (32\%) receiving an average dose of $1.3 \times 10^{11}$ TILs, no localization to metastatic sites was observed, while TILs were trapped in the lungs and in the RES of lymphatic organs. None experienced tumor regression. Among the remaining 26 patients who experienced tumor localization, only 10 $(38 \%)$ responded. This momentous study underlines the dichotomy between systemic and on-target factors that determine the TI

An extreme example of critical problems in ACT is the death of a patient who received $1 \times 10^{10} \mathrm{~T}$ cells engineered to express a third-generation anti-HER2 CAR construct that included (besides the $\mathrm{CD} 3 \zeta$ chain) both costimulatory molecules 4-1BB and CD28. ${ }^{19}$ CAR-T cells were administered in combination with high-dose systemic interleukin (IL)-2 and lymphodepletion. Uncontrollable CRS and respiratory failure ensued. Toxicity was attributed to 'on-target, off-tumor toxicity' as HER2 is expressed by normal lung epithelium and 'on-target, on-tumor toxicity' due to killing of HER2+ cancer cells in lung metastases possibly resulting in 'tumor lysis syndrome'. However, the administration of IL-2, which induces uncontrolled cytokine release, increases capillary leakage, activates the RES and turns normal tissues into acutely inflamed sites with chemoattractive and T-cell stimulatory properties ${ }^{11}$ might have derailed the CAR-T cells promoting leakage into normal organs and lowering their threshold for activation in the context of acute inflammation. Subsequent studies utilizing a second-generation CAR construct and no administration of IL-2 demonstrated limited on-target/off-tumor toxicity. ${ }^{20} 21$

\section{TME-SPECIFIC FACTORS}

The balance between the chemoattractive and immunemodulatory properties of benign versus neoplastic tissue regulates the deployment of ACT products. Since benign tissues are generally not inflamed and, therefore, nonchemoattractive, ACT products will barely engage with them, trafficking preferentially to inflamed tumors. We propose that this differential is a key TME-specific crossroad determining theTI in solid malignancies (figure 1). For instance, Castellarin et $a l^{14}$ developed an immunedeficient mouse model expressing human HER2 in normal hepatic tissue. On-target/off-tumor toxicity was compared between two affinity-tuned HER2-specific CAR-T cells. In mice expressing high levels of human HER2, both highaffinity and low-affinity CAR-T cells caused lethal toxicity. In mice expressing low levels of human HER2, no liver toxicity was noted and, surprisingly, low-avidity CAR-T cells displayed stronger anti-tumor activity. Low-affinity CAR-T cells migrated out of the liver and infiltrated the tumor sooner, suggesting lesser compartmentalization in normal, non-inflamed tissues.

\section{T-CELL HOMING ACCORDING TO IMMUNE LANDSCAPE}

Response to immunotherapy is predicted by pre-existing inflammation. $^{22}$ Transcriptional patterns such as the 
immunologic constant of rejection (ICR) ${ }^{23}$ or the tumor inflammation signature ${ }^{24}$ demonstrated that the activation of IFN- $\gamma$ signaling, immune-effector mechanisms and the expression of CCR5 and CXCR3 ligand chemokines stand as independent predictors. Thus, based on the presence of $\mathrm{T}$ cells, their spatial distribution and functional orientation, human solid tumors are partitioned into three immune landscapes distributed at approximately equal frequency among cancers of different histology: 'immune-active, infiltrated or hot', 'immune-silent, desert or cold' and 'immune-excluded'. ${ }^{25}$ Attraction of T cells is favored by an inflamed, chemoattractive TME, while cold tumors and non-inflamed benign tissues rest ignored. Immune-excluded tumors sit astride as a certain degree of chemoattraction seems sufficient to draw $\mathrm{T}$ cells to their periphery.

\section{TUMOR IMMUNOGENICITY AND IMMUNE SUPPRESSION}

Immune-active tumors are characterized by genetic instability and high mutational rate. ${ }^{26}$ We observed that immunogenic cell death (ICD) is a hallmark of this phenotype, correlating tightly with the ICR signature. ${ }^{26} 27$ Moreover, most processes implicated in immune suppression such as the checkpoint cluster, regulatory $\mathrm{T}$ cells, myeloid suppressor cells and metabolic inhibitors dovetail with the immune-active phenotype. ${ }^{27}$ The congregation of immune-effector and immune-regulatory mechanisms within the same landscape suggests that an evolutionary balance is required for the survival of antigenic tumors in the immune-competent host, where compensatory immune resistance offset immunogenicity. ${ }^{27}$ Adoptivelytransferred $\mathrm{T}$ cells may innately infiltrate immune-active tumors lured by chemoattraction but face diverse challenges within the TME, becoming dysfunctional because of overwhelming immune suppression and metabolic derangement.

\section{METABOLIC STRESS}

Dysfunction of $\mathrm{T}$ cells is a hallmark of neoplasia and determines the outcome of anti-cancer immunotherapy. ${ }^{28}$ On antigen stimulation, CTLs transition to an active state, requiring intensive energy production. Following expansion, most $\mathrm{T}$ cells undergo apoptotic death while a smaller proportion returns to a quiescent anamnestic state. These evolutionary stages are echoed by metabolic transitions allowing $\mathrm{T}$ cells to adapt to regional and functional differences, respond to context-specific demands and reprogram energy production. These physiologic processes are disrupted in the TME that limits the availability of nutrients in competition with the high energy consumption of replicating cancer cells and the stromal response. Thus, the TME is characterized by heightened consumption of glucose and essential amino acids such as glutamine, tryptophan, cysteine, glycine and arginine. ${ }^{29}$ Metabolic derangement is compounded by hypoxic conditions that induce the production of immune-suppressive byproducts such as lactate, adenosine and kynurenine. ${ }^{30}$ Moreover, hypoxia-inducible factor $\alpha$ activates transforming growth factor- $\beta$ and other soluble elements that bear powerful effects on T-cell trafficking, differentiation and function. ${ }^{31}$

\section{TARGET ENGAGEMENT}

The presence of $\mathrm{T}$ cells at the periphery of tumor nests defines the phenomenon of immune exclusion. A recent study characterized by immunohistochemistry the topography of immune infiltration in approximately 1000 tumor specimens demonstrating that immune exclusion occurs in a third of cancers across several histologies. ${ }^{25}$ Without knowledge about T-cell spatial distribution, immuneexcluded cancers are functionally indistinguishable from the immune-active. By applying the ICR signature to head and neck carcinoma samples, we observed that both immune-excluded and immune-infiltrated tumors display an immune-effector Th1-like signature (Pai et al, ASCO 2018, Abstract \# 6052). Since the ICR includes Th1 polarization markers activated by antigen exposure, it is likely that $\mathrm{T}$ cells come into contact with and recognize cancer cells at the border of the tumor nest but a functional barrier prevents further progression toward the core. Thus, trafficking of T cells to immune-excluded cancers is comparable to the immune-active since in both cases, chemoattraction recruits $\mathrm{T}$ cells to the tumor and some immunogenic stimulus promotes their persistence. The biology determining the two phenotypes diverges at this point: in inflamed tumors, no chemorepulsive signals hamper penetration but immune suppression dampens the function of T cells; immune-excluded tumors act like immune privileged tissue through chemorepulsion, while immune suppression plays a limited role. Functional barriers may not be present in baseline conditions but they may be induced when contact occurs between $\mathrm{T}$ cells and cancer cells: for instance, on encounter with tumor cells, T cells release IFN- $\gamma$ which, in turn, induces the activation of dynamic barriers such as the expression of programmed death-ligand $1 .{ }^{32}$ Moreover, the expression of genes regulating physical barriers is, in some cases, inversely correlated with the ICR signature, ${ }^{33}$ suggesting an alternative mechanism of immune-exclusion when mechanical barriers prevent T-cell infiltration. Here, no direct contact occurs between cancer cells and $\mathrm{T}$ cells and, therefore, no activation of immune-effector gene signatures can be observed.

\section{PERIPHERAL IGNORANCE}

While inflamed and immune-excluded tumors are spontaneously chemoattractive, desert cancers may rest in peace ignored by immune cells. ${ }^{25} 27$ Indeed, immunedesert tumors are genetically stable, bear low mutational rates and lack ICD, closely approximating the biology of normal benign tissues and representing the ultimate challenge toward an optimal TI for ACT products. 


\section{IMAGING TO PREDICT AND MONITOR THE TI}

In this commentary, we speculate that a fundamental determinant of the TI for ACT of solid tumors is the baseline status of inflammation of benign versus neoplastic tissues. This differential directs homing of $\mathrm{T}$ cells through chemoattraction while persistence is promoted by co-stimulatory signals in situ. Yet, no mapping of a given patient's inflammatory status is considered in pre-treatment assessments, while it is done to evaluate chronic inflammation in the context of cardiometabolic and autoimmune disorders. ${ }^{3435}$ A similar organ-specific mapping could categorize inflammation in the cancer-bearing host serving as a patient-specific predictor. Moreover, homing of infused $\mathrm{T}$ cells could be tracked by functional MRI, exploiting the metabolism of activated T cells. ${ }^{36}$ This strategy offers the opportunity to evaluate reasons for on-target/off-tumor effects during treatment.

\section{COMBINATORIAL APPROACHES TO INCREASE THE TI Converting cold into hot tumors}

Cold tumors represent the ultimate challenge for ACT since the absence of $\mathrm{T}$ cells suggests lack of chemoattraction. Can a temporary disruption of their stealth biology open a window of opportunity for ACT? Most chemotherapeutic agents kill cancer cells in a non-immunogenic manner. However, some such as anthracyclines and oxaliplatin can induce ICD. ${ }^{37}$ Pathway inhibitors can create an immunogenic TME by interfering with intrinsic cancer cell biology. A KRAS inhibitor induced a pro-inflammatory switch in immune-competent models, improving tumor control when used in combination with checkpoint inhibitor therapy (CIT) ${ }^{38}$ Levantinib, an inhibitor of the vascular endothelial growth factor receptor, induced CTL infiltration and enhanced effectiveness of CIT. ${ }^{39}$ In addition, BRAF and CDK4/6 inhibitors in combination with MEK inhibitors induce activation of CTLs, contributing to anti-tumor effects. ${ }^{40}$ Oncolytic virotherapy promotes intra-tumoral T-cell infiltration, improving the effectiveness of CIT. ${ }^{41}$ Although these observations relate to CIT, immune conversion of cold tumors may also open a window of opportunity for the attraction of ACT products to the tumor site.

\section{Multitargeting}

The effectiveness of CAR-T cells aimed at a single antigen is limited by selection of antigen negative cancer cells. In addition, CAR-T cell targets are rarely exclusive to cancer cells, leaving space for on-target toxicity. Fine tuning of CAR affinity may reduce on-target/off-tumor effects. ${ }^{14} 42$ Dual targeting of antigens co-expressed by tumor cells may either increase specificity or decrease chances for tumor escape according to the conditionality of their activation: if both antigens are required for full CAR-T cell activation specificity for neoplastic tissues is enhanced while if either one is sufficient for activation tumor escape will occur only with both antigens' expression is lost but specificity will be dampened. Two CAR constructs can be included into the same product. ${ }^{43}$ Bi-specific CARs with two extracellular binding motifs sharing the same intracellular signaling have been tested in hematologic malignancies. ${ }^{44}$ Multiple antigens can also be targeted by universal CARs directed toward a soluble antigen-binding adaptor. ${ }^{45}$

It is not clear, however, whether dual targeting may increase chances of on-target/off-tumor toxicity affecting benign tissues expressing either antigen. To reduce such risk, dual CAR-T cells can be conditionally activated only when both antigens are co-expressed by tumor cells.

\section{Conditional modulation of T-cell function}

Lymphodepleting chemotherapy is an established adjunct to ACT by conditioning the host for optimal engraftment and expansion of transferred T cells, ${ }^{46}$ although indirect immune suppressive mechanisms can be triggered such as the overexpansion of myeloid suppressor cells. ${ }^{47}$ To date, lymphodepletion remains a cardinal combination for most ACT protocols aimed at the treatment of solid tumors, while approaches to increase T-cell persistence are being sought to bypass this need. Indeed, combining other synergistic anti-cancer approaches may enhance effectiveness. The combination of ACT with CIT can revive a cellular product otherwise driven to exhaustion by tonic antigen stimulation and co-inhibitory signaling. ${ }^{48}$ A limitation to combinatorial approaches directed against solid tumors remains our poor understanding of the biology of synergisms related to different immune landscapes. As a result, empirical attempts have been so far discouraging. Moreover, while binary approaches are relatively easy to justify due to fairly predictable cumulative toxicity, multiplicity of approaches exponentially increase the risk of combined toxicities, suffer additional costs and, from the trial perspective, add a number of permutations to be tested that go beyond realistic expectations for patient recruitment.

To alleviate some of these issues, new synthetic biology approaches combine several mechanisms of action within one product such as 'armored' CAR-T cells constitutively secreting homeostatic cytokines and pro-inflammatory ligands, ${ }^{49}$ or delivering anti-programmed cell death-1 (PD-1) scFvc. ${ }^{50}$ Genetic knockout of the PD-1 gene ${ }^{51}$ or genetic engineering of Fas variants insensitive to Fasligand-induced apoptosis enhance persistence and antitumor effects. ${ }^{52}$ The site of transgene integration during the engineering of T-cell products can also significantly improve CAR-T cell function. ${ }^{53}$ To mitigate the effects of inhibitory signals, chimeric 'switch receptors' combine an external domain receptor for a T-cell inhibitor, such as IL-4 fused to the signaling domain of an activating molecule such as IL-7 to turn inhibitory into stimulatory signals. ${ }^{54}$ Lynn et $a l^{55}$ observed that overexpression of c-Jun prevents CAR-T cells exhaustion and improves antitumor efficacy. Moreover, the overexpression of the oncogene prevented expression of exhaustion markers such as PD-1. These constitutive approaches lead, however, to permanent alterations of the DNA structure and increased 
the risk for neoplastic transformation, particularly when master regulators of cellular proliferation are involved.

Novel approaches adopt synthetic notch receptors to induce transcriptional activation of various regulatory programs in $\mathrm{T}$ cells in response to antigen encounter. ${ }^{56}$ Similarly, a non-gene editing, non-permanent, conditional regulation of cellular programs adopts an antigen encounter-dependent nuclease-deactivated CRISPR (clustered regularly interspaced short palindromic repeats)-associated interference system (http://ssrn. com/abstract=3656606). By introducing several singleguide RNAs, it is possible to conditionally prevent in synchrony the activation of multiple genes that have suppressive effects on the CAR-T cells. This strategy is safer than standard gene editing because it is fully reversible and does not cause permanent changes in DNA structure/sequence. At the same time, this approach bypasses severe toxicities due to the systemic administration of immune modulatory products.

\section{CONCLUSION}

Success of ACT against solid tumors will depend on a deeper and precise understanding of individual patient's immune biology and the fine balance that governs distribution, deployment, expansion and activation of infused products. Here, we propose a logical process to define patient selection and therapeutic strategy for an optimal TI Several concepts raised here are speculative, derived from other disciplines or from pre-clinical models. The ultimate test in patients will require thoughtful, though not necessarily, over-burdensome study design to validate the usefulness of this logic. Progress in the treatment of solid cancers will stand a better chance only if systematic non-empirical approaches as the one described here are proactively sought.

Contributors All authors contributed equally to the preparation of the commentary. Funding The authors have not declared a specific grant for this research from any funding agency in the public, commercial or not-for-profit sectors.

Competing interests EW, Allogene Therapeutics; AC, ESSA Pharma; LHB, Parker Institute for Cancer Immunotherapy and University of California San Francisco; and FM, Refuge Biotechnologies.

Patient consent for publication Not required.

Provenance and peer review Not commissioned; externally peer-reviewed.

Open access This is an open access article distributed in accordance with the Creative Commons Attribution Non Commercial (CC BY-NC 4.0) license, which permits others to distribute, remix, adapt, build upon this work non-commercially, and license their derivative works on different terms, provided the original work is properly cited, appropriate credit is given, any changes made indicated, and the use is non-commercial. See http://creativecommons.org/licenses/by-nc/4.0/.

\section{ORCID iD}

Lisa H Butterfield http://orcid.org/0000-0002-3439-9844

\section{REFERENCES}

1 Hill JA, Giralt S, Torgerson TR, et al. CAR-T - and a side order of IgG, to go? - Immunoglobulin replacement in patients receiving CAR-T cell therapy. Blood Rev 2019;38:100596.
2 Burstein HJ. The distinctive nature of HER2-positive breast cancers. N Engl J Med 2005;353:1652-4.

3 lqbal N, lqbal N. Human epidermal growth factor receptor 2 (HER2) in cancers: overexpression and therapeutic implications. Mol Biol Int 2014;2014:1-9.

4 Rivoltini L, Barracchini KC, Viggiano V, et al. Quantitative correlation between HLA class I allele expression and recognition of melanoma cells by antigen-specific cytotoxic T lymphocytes. Cancer Res 1995;55:3149-57.

5 Rossi J, Paczkowski P, Shen Y-W, et al. Preinfusion polyfunctional anti-CD19 chimeric antigen receptor T cells are associated with clinical outcomes in NHL. Blood 2018;132:804-14.

6 Sahoo P, Yang X, Abler D, et al. Mathematical deconvolution of car T-cell proliferation and exhaustion from real-time killing assay data. $J$ $R$ Soc Interface 2020;17:20190734.

7 Klebanoff CA, Gattinoni L, Torabi-Parizi P, et al. Central memory self/ tumor-reactive CD8+ T cells confer superior antitumor immunity compared with effector memory T cells. Proc Natl Acad Sci U S A 2005;102:9571-6.

8 Gattinoni L, Speiser DE, Lichterfeld M, et al. T memory stem cells in health and disease. Nat Med 2017;23:18-27.

9 Sommermeyer D, Hill T, Shamah SM, et al. Fully human CD19specific chimeric antigen receptors for T-cell therapy. Leukemia 2017;31:2191-9.

10 Panelli MC, Martin B, Nagorsen D, et al. A genomic- and proteomicbased hypothesis on the eclectic effects of systemic interleukin-2 administration in the context of melanoma-specific immunization. Cells Tissues Organs 2004;177:124-31.

11 Panelli MC, Wang E, Phan G, et al. Gene-Expression profiling of the response of peripheral blood mononuclear cells and melanoma metastases to systemic IL-2 administration. Genome Biol 2002;3:RESEARCH0035.

12 Lee P-H, Yamamoto TN, Gurusamy D, et al. Host conditioning with IL-1 $\beta$ improves the antitumor function of adoptively transferred T cells. J Exp Med 2019;216:2619-34.

13 Pockaj BA, Sherry RM, Wei JP, et al. Localization of 111Indiumlabeled tumor infiltrating lymphocytes to tumor in patients receiving adoptive immunotherapy. augmentation with cyclophosphamide and correlation with response. Cancer 1994;73:1731-7.

14 Castellarin M, Sands C, Da T, et al. A rational mouse model to detect on-target, off-tumor CAR T cell toxicity. JCl Insight 2020;5:e136012.

15 Critchley-Thorne RJ, Simons DL, Yan N, et al. Impaired interferon signaling is a common immune defect in human cancer. Proc Natl Acad Sci U S A 2009;106:9010-5.

16 Liu Q, Tomei S, Ascierto ML, et al. Melanoma NOS1 expression promotes dysfunctional IFN signaling. J Clin Invest 2014;124:2147-59.

17 Cerrano M, Ruella M, Perales M-A, et al. The advent of car T-cell therapy for lymphoproliferative neoplasms: integrating research into clinical practice. Front Immunol 2020;11:888

18 Bedognetti D, Ceccarelli M, Galluzzi L, et al. Toward a comprehensive view of cancer immune responsiveness: a synopsis from the SITC workshop. J Immunother Cancer 2019;7:131.

19 Morgan RA, Yang JC, Kitano M, et al. Case report of a serious adverse event following the administration of T cells transduced with a chimeric antigen receptor recognizing ErbB2. Mol Ther 2010;18:843-51.

20 Ahmed N, Brawley V, Hegde M, et al. Her2-Specific chimeric antigen receptor-modified virus-specific T cells for progressive glioblastoma: a phase 1 dose-escalation trial. JAMA Oncol 2017;3:1094-101.

21 Feng K, Liu Y, Guo Y, et al. Phase I study of chimeric antigen receptor modified T cells in treating HER2-positive advanced biliary tract cancers and pancreatic cancers. Protein Cell 2018;9:838-47.

22 Wang E, Miller LD, Ohnmacht GA, et al. Prospective molecular profiling of melanoma metastases suggests classifiers of immune responsiveness. Cancer Res 2002;62:3581-6.

23 Wang E, Worschech A, Marincola FM. The immunologic constant of rejection. Trends Immunol 2008;29:256-62.

24 Ayers M, Lunceford J, Nebozhyn M, et al. IFN- $\gamma$-related mRNA profile predicts clinical response to PD-1 blockade. J Clin Invest 2017;127:2930-40.

25 Kather JN, Suarez-Carmona M, Charoentong P, et al. Topography of cancer-associated immune cells in human solid tumors. Elife 2018; 7:e36967.

26 Roelands J, Hendrickx W, Zoppoli G, et al. Oncogenic states dictate the prognostic and predictive connotations of intratumoral immune response. J Immunother Cancer 2020;8:e000617.

27 Turan T, Kannan D, Patel M, et al. Immune oncology, immune responsiveness and the theory of everything. $J$ Immunother Cancer 2018:6:50. 
28 Sukumar M, Kishton RJ, Restifo NP. Metabolic reprograming of antitumor immunity. Curr Opin Immunol 2017;46:14-22.

29 O'Neill LAJ, Kishton RJ, Rathmell J. A guide to immunometabolism for immunologists. Nat Rev Immunol 2016:16:553-65.

30 Pavlova NN, Thompson CB. The emerging hallmarks of cancer metabolism. Cell Metab 2016;23:27-47.

31 Mariathasan S, Turley SJ, Nickles D, et al. Tgf $\beta$ attenuates tumour response to PD-L1 blockade by contributing to exclusion of T cells. Nature 2018;554:544-8.

32 Lyford-Pike S, Peng S, Young GD, et al. Evidence for a role of the PD-1:PD-L1 pathway in immune resistance of HPV-associated head and neck squamous cell carcinoma. Cancer Res 2013;73:1733-41.

33 Salerno EP, Bedognetti D, Mauldin IS, et al. Human melanomas and ovarian cancers overexpressing mechanical barrier molecule genes lack immune signatures and have increased patient mortality risk. Oncoimmunology 2016;5:e1240857.

34 Aksentijevich M, Lateef SS, Anzenberg P, et al. Chronic inflammation, cardiometabolic diseases and effects of treatment: psoriasis as a human model. Trends Cardiovasc Med 2019. doi:10.1016/j. tcm.2019.11.001. [Epub ahead of print: 20 Nov 2019].

35 MacRitchie N, Frleta-Gilchrist M, Sugiyama A, et al. Molecular imaging of inflammation - Current and emerging technologies for diagnosis and treatment. Pharmacol Ther 2020;211:107550.

36 Haris M, Bagga P, Hariharan $\mathrm{H}$, et al. Molecular imaging biomarkers for cell-based immunotherapies. J Trans/ Med 2017;15:140.

37 Galluzzi L, Vitale I, Warren S, et al. Consensus guidelines for the definition, detection and interpretation of immunogenic cell death. $J$ Immunother Cancer 2020;8:e000337.

38 Canon J, Rex K, Saiki AY, et al. The clinical KRAS(G12C) inhibitor AMG 510 drives anti-tumour immunity. Nature 2019;575:217-23.

39 Kato Y, Tabata K, Kimura T, et al. Lenvatinib plus anti-PD-1 antibody combination treatment activates CD8+ T cells through reduction of tumor-associated macrophage and activation of the interferon pathway. PLoS One 2019;14:e0212513.

40 Teh JLF, Erkes DA, Cheng PF, et al. Activation of CD8 ${ }^{+} \mathrm{T}$ Cells Contributes to Antitumor Effects of CDK4/6 Inhibitors plus MEK Inhibitors. Cancer Immunol Res 2020;8:1114-21.

41 Ribas A, Dummer R, Puzanov I, et al. Oncolytic virotherapy promotes intratumoral T cell infiltration and improves anti-PD-1 immunotherapy. Cell 2018;174:1031-2.

42 Drent $\mathrm{E}$, Themeli M, Poels R, et al. Reducing on-target Off-Tumor effects of CD38-Chimeric antigen receptors by affinity optimization. Blood 2016;128:2170.
43 Ruella M, Barrett DM, Kenderian SS, et al. Dual CD19 and CD123 targeting prevents antigen-loss relapses after CD19-directed immunotherapies. J Clin Invest 2016;126:3814-26.

44 Song M-K, Park B-B, Uhm J-E. Resistance mechanisms to CAR T-cell therapy and overcoming strategy in B-cell hematologic malignancies. Int J Mol Sci 2019;20:5010.

45 Cho JH, Collins JJ, Wong WW. Universal chimeric antigen receptors for multiplexed and logical control of T cell responses. Cell 2018;173:1426-38. e11.

46 Wallen $\mathrm{H}$, Thompson JA, Reilly JZ, et al. Fludarabine modulates immune response and extends in vivo survival of adoptively transferred CD8 T cells in patients with metastatic melanoma. PLoS One 2009;4:e4749.

47 Innamarato P, Kodumudi K, Asby S, et al. Reactive myelopoiesis triggered by Lymphodepleting chemotherapy limits the efficacy of adoptive T cell therapy. Mol Ther 2020. doi:10.1016/j. ymthe.2020.06.025. [Epub ahead of print: 24 Jun 2020].

48 Wang H, Kaur G, Sankin Al, et al. Immune checkpoint blockade and CAR-T cell therapy in hematologic malignancies. J Hematol Oncol 2019;12:59.

49 Yeku OO, Brentjens RJ. Armored CAR T-cells: utilizing cytokines and pro-inflammatory ligands to enhance CAR T-cell anti-tumour efficacy. Biochem Soc Trans 2016;44:412-8.

50 Rafiq S, Yeku OO, Jackson HJ, et al. Targeted delivery of a PD-1blocking scFv by CAR-T cells enhances anti-tumor efficacy in vivo. Nat Biotechnol 2018;36:847-56.

51 Stadtmauer EA, Fraietta JA, Davis MM, et al. CRISPRengineered T cells in patients with refractory cancer. Science 2020;367:eaba7365

52 Yamamoto TN, Lee P-H, Vodnala SK, et al. T cells genetically engineered to overcome death signaling enhance adoptive cancer immunotherapy. J Clin Invest 2019;129:1551-65.

53 Eyquem J, Mansilla-Soto J, Giavridis T, et al. Targeting a car to the TRAC locus with CRISPR/Cas9 enhances tumour rejection. Nature 2017;543:113-7.

54 Bajgain P, Tawinwung S, D'Elia L, et al. Car T cell therapy for breast cancer: harnessing the tumor milieu to drive $T$ cell activation. $J$ Immunother Cancer 2018;6:34.

55 Lynn RC, Weber EW, Sotillo E, et al. C-Jun overexpression in car T cells induces exhaustion resistance. Nature 2019;576:293-300.

56 Roybal KT, Williams JZ, Morsut L, et al. Engineering T cells with customized therapeutic response programs using synthetic Notch receptors. Cell 2016;167:419-32. e16. 